\title{
CHRYSOPHYLLUM L. (SAPOTACEAE) DA BAHIA: ANATOMIA FOLIAR APLICADA À TAXONOMIA
}

\author{
Rísia Cean Silva de Lima Santos ${ }^{1}$ e Cláudia Elena Carneiro ${ }^{2}$ \\ 1. Bolsista PIBIC/FAPESB, Graduanda em Ciências Biológicas, Universidade Estadual de Feira de Santana, e-mail: \\ risiacean@hotmail.com \\ 2. Orientadora, Departamento de Ciências Biológicas, Universidade Estadual de Feira de Santana, e-mail: \\ carneiro@uefs.br
}

PALAVRAS-CHAVE: Sapotaceae; Morfologia; Chrysophyllum

\section{INTRODUÇÃO}

Sapotaceae é uma das inúmeras famílias que compõem a flora da Bahia, ocupando lugar de destaque em ambientes florestais, sendo representada por árvores e arbustos que são reconhecidos facilmente devido à combinação do látex com o arranjo e venação das folhas (Gentry, 1993). Atualmente, 12 gêneros e 232 espécies ocorrem no Brasil, dentre os quais, para a Bahia, há 77 espécies distribuídas em 11 gêneros (Carneiro et al., 2016). Os gêneros dessa família apresentam problemas na delimitação de suas espécies, a nível taxonômico, que dificultam a identificação correta de seus táxons, principalmente devido à ausência ou carência de dados morfológicos que sustentem as relações entre eles. Chrysophyllum L. é o segundo maior gênero de Sapotaceae em número de espécies, abrangendo em torno de 43 espécies na região neotropical (Pennington, 1990). Para a Bahia, são citadas até o momento 12 espécies (Carneiro et al., 2016), das quais nove foram investigadas recentemente (dados não publicados). Com o avanço tecnológico e o surgimento de ferramentas que auxiliam na taxonomia dos grupos, existe a necessidade de um levantamento de maiores informações sobre o táxon em foco. Assim, a busca de detalhes torna-se essencial para o entendimento do organismo que vive em diversos ecossistemas baianos, fornecendo vários produtos, que no conjunto propiciarão uma melhoria do conhecimento disponível sobre a flora do Estado. O objetivo deste trabalho foi identificar e caracterizar as espécies de Chrysophyllum L. ocorrentes no estado da Bahia, utilizando a anatomia foliar.

\section{METODOLOGIA}

Primeiramente foi feito o levantamento e a identificação dos táxons através de consulta a herbário e bibliografia específica, seguido pela coleta de material botânico em campo e em herbário. O processamento das amostras foi feito utilizando técnicas comumente empregadas em estudos morfológicos e taxonômicos para material herborizado e para material fresco, (Johansen 1940; Kraus \& Arduin 1997; Macêdo 1997). As lâminas foram montadas utilizando meios semi-permanentes e permanentes. A análise morfológica foi realizada em microscopia de luz, culminando na descrição dos produtos, e a realização de fotomicrografias dos táxons, destacando os caracteres mais significativos.

\section{RESULTADOS E DISCUSSÃO}

Dentre as 12 espécies de Chrysophyllum ocorrentes na Bahia, foram analisadas nove espécies: C. arenarium Allemão, C. flexuosum Mart., C. gonocarpum (Mart. \& Eichler ex Miq.) Engl., C. inornatum Mart., C. januariense Eichler, C. lucentifolium Cronquist, C. marginatum (Hook. \& Arn.) Radlk, C. rufum Mart., e C. splendens Spreng. A caracterização anatômica das folhas das espécies estudadas é apresentada a seguir.

A epiderme em Chrysophyllum marginatum (Hook. \& Arn.) Radlk. apresenta poucas cicatrizes de tricomas e presença de estômatos sobre a nervura principal na face adaxial; 
na face abaxial, as células da epiderme diferem apenas no tamanho, sendo menores que as células observadas da superfície adaxial, e os estômatos são do tipo anisocíticos. Em Chrysophyllum gonocarpum (Mart. \& Eichler ex Miq.) Engl., as folhas são anfiestomáticas, com estômatos paracíticos em maior quantidade na superfície abaxial, e a epiderme apresenta células retangulares e tricomas malpiguiáceos. Chrysophyllum rufum Mart., apresentou na face adaxial células epidérmicas mais poligonais e, nas bases dos tricomas em grupos de 4-6 células; na superfície abaxial há presença de estômatos do tipo anisocítico e apresenta cutícula espessa. Em Chrysophyllum splendens Spreng., as faces adaxial e abaxial da lâmina foliar são formadas por células poligonais; a face abaxial apresenta estômatos do tipo anisocítico, caracterizando a folha como hipoestomática. Em Chrysophyllum flexuosum Mart., em vista frontal, a epiderme abaxial é caracterizada como hipoestomática, com estômatos do tipo anisocíticos, apresenta células costais retangulares com contorno liso, de 4 a 6 células poligonais na base dos tricomas que são do tipo malpighiáceo; a epiderme adaxial contém células intercostais poligonais com contorno sinuoso e células costais retangulares com contorno levemente sinuoso, de 4 a 6 células poligonais na base dos tricomas (malpiguiáceos), enquanto nas folhas de Chrysophyllum inornatum Mart., a epiderme apresenta células poligonais, de parede anticlinal sinuosa; a face abaxial apresenta estômatos dos tipos diacíticos e paracíticos, caracterizando a folha como hipoestomática, e apresentando cicatrizes dos tricomas com células da base em número de 5-7. Chrysophyllum lucentifolium Cronquist., apresenta células poligonais com paredes anticlinais em alto grau de sinuosidade, idioblastos e tricomas malpiguiáceos; as folhas são hipoestomáticas com estômatos do tipo anomocíticos. Em Chrysophyllum januariense Eichler., ambas as faces da folha apresentaram estômatos do tipo anisocítico, caracterizando-a como anfiestomática; presença de tricomas malpiguiáceos na superfície inferior, com 6-8 células na base.

A organização do mesofilo para todas as amostras analisadas é dorsiventral, apresentando variações. O pecíolo das amostras analisadas apresentou características semelhantes variando apenas no tamanho e na quantidade de laticíferos e cristais encontrados. A organização do sistema vascular também permanece similar. Chrysophyllum arenarium Allemão apresenta um estrato de parênquima paliçádico, seguido por 6 a 8 estratos de parênquima lacunoso; presença de laticíferos dispostos pelo parênquima e associados à nervura central. Foram observados cristais no mesofilo. A folha de $C$. arenarium apresenta bordo reto, com cutícula pouco espessa nessa região. Em secção transversal, o pecíolo de Chrysophyllum arenarium apresenta tricomas malpiguiáceos. Em Chrysophyllum marginatum, o mesofilo é composto por um estrato de parênquima paliçádico bem evidente, e vários estratos de parênquima lacunoso ocupando cerca de $2 / 3$ do mesofilo. Presença de colênquima no córtex e bordos da folha. Já em Chrysophyllum gonocarpum, composto por dois estratos de parênquima paliçádico, e vários estratos de parênquima lacunoso ocupando cerca de $3 / 4$ do mesofilo e na região da nervura central e no pecíolo; laticíferos estão distribuídos por toda a região central, sendo mais evidente no córtex. Em Chrysophyllum rufum, o mesofilo é composto por uma camada de parênquima paliçádico, e de 7 a 8 estratos de clorênquima lacunoso. Ocorrem laticíferos nas proximidades da nervura central e feixes vasculares; o bordo é fortemente fletido com cutícula formando flanges e epiderme mais espessa nesta região. O pecíolo possui epiderme com numerosos tricomas. A folha de Chrysophyllum splendens, em secção transversal, apresenta 7 estratos de parênquima paliçádico, seguido por 4 estratos de parênquima lacunoso; presença de laticíferos dispostos pelo parênquima e associados à nervura central e bordo levemente fletido. O pecíolo, em secção transversal, apresenta tricomas malpiguiáceos, de forma isolada. Chrysophyllum flexuosum, apresenta uma camada de parênquima paliçádico e várias camadas de parênquima esponjoso compondo o mesofilo e laticíferos associados aos feixes vasculares; no córtex existem cerca de três 
estratos de colênquima junto à epiderme. $\mathrm{O}$ bordo é fletido e o pecíolo tem formato de cilindro vascular colateral; presença de cristais prismáticos no córtex e laticíferos principalmente em torno do cilindro vascular. Chrysophyllum inornatum apresenta apenas uma camada de células epidérmicas, com até 3 estratos de parênquima paliçádico e 8 estratos de parênquima esponjoso; cutícula espessa em ambas as faces; laticíferos presentes na região cortical da nervura central; bordo foliar levemente fletido, cutícula não formando flanges. Apresenta pecíolo com epiderme recoberta por tricomas malpiguiáceos, cutícula espessa, e laticíferos distribuídos por toda região. Em Chrysophyllum lucentifolium Cronquist., o mesofilo é composto por 2 estratos de parênquima paliçádico e 9 estratos de parênquima lacunoso; os laticíferos estão distribuídos por toda a região central; presença de colênquima no córtex e no bordo, apresentando resíduos de látex. Em Chrysophyllum januariense, o mesofilo é composto por 3 camadas de parênquima paliçádico e 8 estratos de parênquima esponjoso; os laticíferos ocorrem nas proximidades da nervura central e feixes vasculares; bordo levemente fletido e cutícula pouco espessa nesta região. O pecíolo possui epiderme com numerosos tricomas.

De acordo com os estudos realizados, as espécies de Chrysophyllum L. apresentaram características que são comuns ao gênero, como paredes anticlinais sinuosas, mesofilo dorsiventral e presença de laticíferos. Entretanto, o tipo de estômato varia entre anomocítico, paracítico e anisocítico, assim como a caracterização das folhas em hipoestomáticas ou anfiestomáticas. Outras características se mostraram persistentes na maioria das espécies durantes as análises, como o tipo de tricoma - malpighiáceo, o número de células da camada epidérmica e células de paredes retas. Dessa maneira, foi possível concluir a identificação das espécies, tendo como base as características morfoanatômicas que elas apresentam, características estas que sofrem influência do meio em que vivem, assim como das condições a que são expostas.

\section{CONSIDERAÇÕES FINAIS}

A partir destes estudos foi possível realizar o levantamento das características anatômicas das folhas de espécies de Chrysophyllum L., ocorrentes na Bahia. Algumas características da anatomia foliar possuem grande importância para as análises taxonômicas. Convém mencionar que não há estudos de anatomia foliar para o gênero. Acredita-se na investigação de caracteres micromorfológicos que possam colaborar com estudos de outra natureza, constituindo mais uma ferramenta para a compreensão e circunscrição das espécies estudadas, ressaltando que o trabalho desenvolvido é pioneiro nessa área.

\section{REFERÊNCIAS}

CARNEIRO, C.E.; ALVES-ARAUJO, A.; ALMEIDA JR., E.B.; TERRA-ARAÚJO, M.H. 2016. Sapotaceae. In Lista de Espécies da Flora do Brasil. Jardim Botânico do Rio de Janeiro. <http://www.floradobrasil.jbrj.gov.br/jabot/floradobrasil/FB217>.

GENTRY, A.H. 1993. A field guide to the families and genera of woody plants of northeast South America. Washington, D.C., Conservation International.

JOHANSEN, D.A. 1940. Plant Microtechnique. New York, Mc Graw Hill Book.

KRAUS, J.E. \& ARDUIN, M. 1997. Manual básico de métodos em morfologia vegetal. Rio de Janeiro, EDUR.

MACÊDO, N.A. 1997. Manual de Técnicas em Histologia Vegetal. Feira de Santana: Universidade Estadual de Feira de Santana, 98p.

PENNINGTON, T.D. 1990. Sapotaceae. Flora Neotropica 52: 1-770. 